\title{
Histochemical Demonstration of $\alpha$-Glucan Phosphorylase Activity in the Human Axillary Apocrine Sweat Gland
}

\author{
Yoichiro Sasai \\ Department of Dermatology (Prof. Y. Takahashi), \\ Tohoku University School of Medicine, Sendai
}

\begin{abstract}
The effect of glycogen and glycogen metabolites on the histochemical reaction of $a$-glucan phosphorylase was examined. The addition of glycogen, dextrin, amylopectin or dextran with a higher molecular weight to the substrate solution was scarcely effective in shortening incubation time necessary for the appearance of a positive reaction. In contrast, when dextran with a lower molecular weight was introduced into the substrate solution, the incubation time necessary for the appearance of the reaction was shortened. By the use of dextran-containing substrate solution, the activity of a-glucan phosphorylase in the human axillary apocrine sweat gland could be demonstrated.
\end{abstract}

$\alpha$-Glucan phosphorylase known to be capable of cleaving the glucosidic bonds of glycogen exists in two different forms, phosphorylase $a$ and phosphorylase $b$. Phosphorylase $a$ does not require the presence of any co-factor for its activity, whereas phosphorylase $b$ is inactive unless $5^{\prime}$-adenylic acid is added. The interconversion of these two forms is the result of a specific phosphatase activity which splits phosphate from phosphoserine groups, and of a specific kinase activity which transfers phosphate from adenosine triphosphate to serine. The former is suppressed by sodium fluoride, and the latter by ethylenediaminetetraacetic acid.

The histochemical method for demonstrating $\alpha$-glucan phosphorylase was first devised by Yin and Sun, ${ }^{1}$ and was placed on a stable footing by the studies of Takeuchi and his co-workers. ${ }^{2-4}$ With the method proposed by them, several workers $^{5-9}$ surveyed the localization and the relative concentration of $\alpha$-glucan phosphorylase in human skin. It has been shown that the secretory portion of the eccrine sweat gland is rich in $\alpha$-glucan phosphorylase, while the secretory portion of the apocrine sweat gland has no activity of the enzyme. However, the fact that the apocrine secretory portion rarely contains glycogen in appreciable amounts ${ }^{10}$ suggests the presence of $\alpha$-glucan phosphorylase in it. The present paper is concerned with the histochemical method for the demonstration of a-glucan phosphorylase activity in the human axillary apocrine sweat gland.

\section{Materials and Methods}

Biopsy skin specimens were obtained from the axillae of healthy males at the age of

Received for publication, September 12, 1968. 
18 to 25 years. As soon as the specimens were excised, they were frozen in small blocks by being immersed in isopentane chilled with liquid nitrogen. Sections were cut at $8 \mu$ in a cryostat maintained at $-20^{\circ} \mathrm{C}$, and were mounted on coverslips. They were dried for 5 minutes in air and incubated at $37^{\circ} \mathrm{C}$ for predetermined periods in Coplin jars, each of which contained $15 \mathrm{mg}$ of sodium fluoride, $20 \mathrm{mg}$ of ethylenediaminetetraacetic acid, $10 \mathrm{ml}$ of $0.05 \mathrm{M}$ acetate buffer ( $\mathrm{pH} 5.8$ ) and glucose-1-phosphate in a final concentration of 0.1 to $100 \mathrm{mM}$. At the end of each incubation period some sections were taken out, and after briefly washed in $40 \%$ ethanol, they were immersed for 30 minutes in Lugol's iodine-iodide solution, which was diluted 10 times with distilled water. They were dried in air and mounted with glycerin. The observations of the slides thus prepared were carried out by continuous use of the same binocular microscope, and the time when a positive reaction was first discernible was recorded as the end point of a-glucan phosphorylase reaction on a given slide. The control substrate solution contained no glucose-1-phosphate. All the control tests were negative.

The dipotassium salt of glucose-1-phosphate and the sodium salt of $5^{\prime}$-adenylic acid from muscle were obtained from Sigma Chem., Co., St. Louis. Glycogen, amylopectin, dextrin, phlorizin glucose and $\alpha$-amylase were supplied from Wako Pure Chem. Indust., Osaka. Dextran was obtained from Seikagaku Kyogo Co., Tokyo.

\section{Orservations}

\section{1) Effect of glucose-1-phosphate concentration on a-glucan phosphorylase reaction}

In the secretory portion of the eccrine sweat gland, $\alpha$-glucan phosphorylase reaction appeared in 5 minutes of incubation at a substrate concentration of 25

TABLE 1. Relation of time of appearance of a-glucan phosphorylase reaction with substrate concentration

\begin{tabular}{c|c|c|c|c|c|c}
\hline $\begin{array}{c}\text { Substrate } \\
\text { concentration } \\
(\mathrm{mM})\end{array}$ & \multicolumn{7}{c}{ Time of incubation (min) } \\
\cline { 2 - 7 } & 5 & 15 & 30 & 60 & 90 & 120 \\
\hline \multicolumn{7}{c}{ Eccrine secretory portion } \\
\hline 100 & + & + & + & + & + & + \\
50 & + & + & + & + & + & + \\
25 & + & + & + & + & + & + \\
10 & - & - & + & + & + & + \\
5 & - & - & + & + & + & + \\
2.5 & - & - & - & + & + & + \\
1.0 & - & - & - & - & - & + \\
0.5 & - & - & - & - & - & - \\
0.25 & - & - & - & - & - & - \\
0.1 & - & - & - & - & - & - \\
\hline
\end{tabular}

Apocrine secretory portion

\begin{tabular}{c|c|c|c|c|c|}
\hline 100 & $\cdots$ & - & - & - & - \\
50 & $\cdots$ & - & - & - & - \\
25 & - & - & - & - & - \\
10 & - & - & - & - & - \\
5 & - & - & - & - & - \\
2.5 & - & - & - & - & - \\
1.0 & - & - & - & - \\
0.5 & - & - & - & - \\
0.25 & - & - & - & -
\end{tabular}


TABLE 2. Relation of time of appearance of a-glucan phosporylase reaction to substrate concentration in the presence of $5^{\prime}$-adenylic acid in $3 \mathrm{mM}$

\begin{tabular}{|c|c|c|c|c|c|c|}
\hline \multirow{2}{*}{$\begin{array}{l}\text { Substrate } \\
\text { concentration } \\
(\mathrm{mM})\end{array}$} & \multicolumn{6}{|c|}{ Time of incubation (min) } \\
\hline & 5 & 15 & 30 & 60 & 90 & 120 \\
\hline \multicolumn{7}{|c|}{ Eccrine secretory portion } \\
\hline $\begin{array}{c}100 \\
50 \\
25 \\
10 \\
5 \\
2.5 \\
1.0 \\
0.5 \\
0.25 \\
0.1\end{array}$ & $\begin{array}{l}+ \\
+ \\
+ \\
+ \\
+ \\
+ \\
+ \\
- \\
- \\
-\end{array}$ & $\begin{array}{l}+ \\
+ \\
+ \\
+ \\
+ \\
+ \\
+ \\
+ \\
- \\
-\end{array}$ & $\begin{array}{l}+ \\
+ \\
+ \\
+ \\
+ \\
+ \\
+ \\
+ \\
+ \\
-\end{array}$ & $\begin{array}{l}+ \\
+ \\
+ \\
+ \\
+ \\
+ \\
+ \\
+ \\
+ \\
+\end{array}$ & $\begin{array}{l}+ \\
+ \\
+ \\
+ \\
+ \\
+ \\
+ \\
+ \\
+ \\
+\end{array}$ & $\begin{array}{l}+ \\
+ \\
+ \\
+ \\
+ \\
+ \\
+ \\
+ \\
+ \\
+\end{array}$ \\
\hline \multicolumn{7}{|c|}{ Apocrine secretory portion } \\
\hline $\begin{array}{c}100 \\
50 \\
25 \\
10 \\
5 \\
2.5 \\
1.0 \\
0.5 \\
0.25 \\
0.1\end{array}$ & $\begin{array}{l}- \\
- \\
- \\
- \\
- \\
- \\
- \\
- \\
-\end{array}$ & $\begin{array}{l}- \\
- \\
- \\
- \\
- \\
- \\
- \\
- \\
-\end{array}$ & $\begin{array}{l}- \\
- \\
- \\
- \\
- \\
- \\
- \\
- \\
- \\
-\end{array}$ & $\begin{array}{l}- \\
- \\
- \\
- \\
- \\
- \\
- \\
- \\
-\end{array}$ & $\begin{array}{l}- \\
- \\
- \\
- \\
- \\
- \\
- \\
- \\
-\end{array}$ & $\begin{array}{l}- \\
- \\
- \\
- \\
- \\
- \\
- \\
-\end{array}$ \\
\hline
\end{tabular}

$\mathrm{mM}$ or in 60 minutes at $2.5 \mathrm{mM}$. In contrast, no reaction was found in the apocrine secretory portion (Table 1).

\section{2) Effect of 5'-adenylic acid on a-glucan phosphorylase reaction}

The addition of $5^{\prime}$-adenylic acid in a concentration of $3 \mathrm{mM}$ or over was effective for the reaction of the eccrine secretory portion and in shortening incubation time necessary for reaching the reaction end point. However, the apocrine secretory portion showed no reaction even when $5^{\prime}$-adenylic acid was added in $10 \mathrm{mM}$ to the substrate solution series (Table 2).

\section{3) Effect of glycogen and glycogen metabolites on a-glucan phosphorylase reaction}

Two substrate solution series were employed: (1) Containing 5'-adenylic acid in $3 \mathrm{mM}$, and (2) 5'-adenylic acid-free series. Glycogen or several glyeogen metabolites such as dextrin, dextran and amylopectin, in a final concentration of 1,10 , 50,100 or $200 \mathrm{mg}$ per $\mathrm{ml}$, were added to the parallel series of substrate solutions.

By the addition of glycogen, dextrin, dextran with an average molecular weight of $2,000,000$ or amylopectin, no conspicuous effect was obtained on the incubation time necessary for reaching the reaction end point or on the distribution of the reaction (Tables 3-5, Fig. 1). However, the addition of dextran with, 
TABLT 3. Effect of glycogen (50 mg per ml) on a-glucan phosphorylase reaction in the presence of $5^{\prime}$-adenylic acid in $3 \mathrm{mM}$

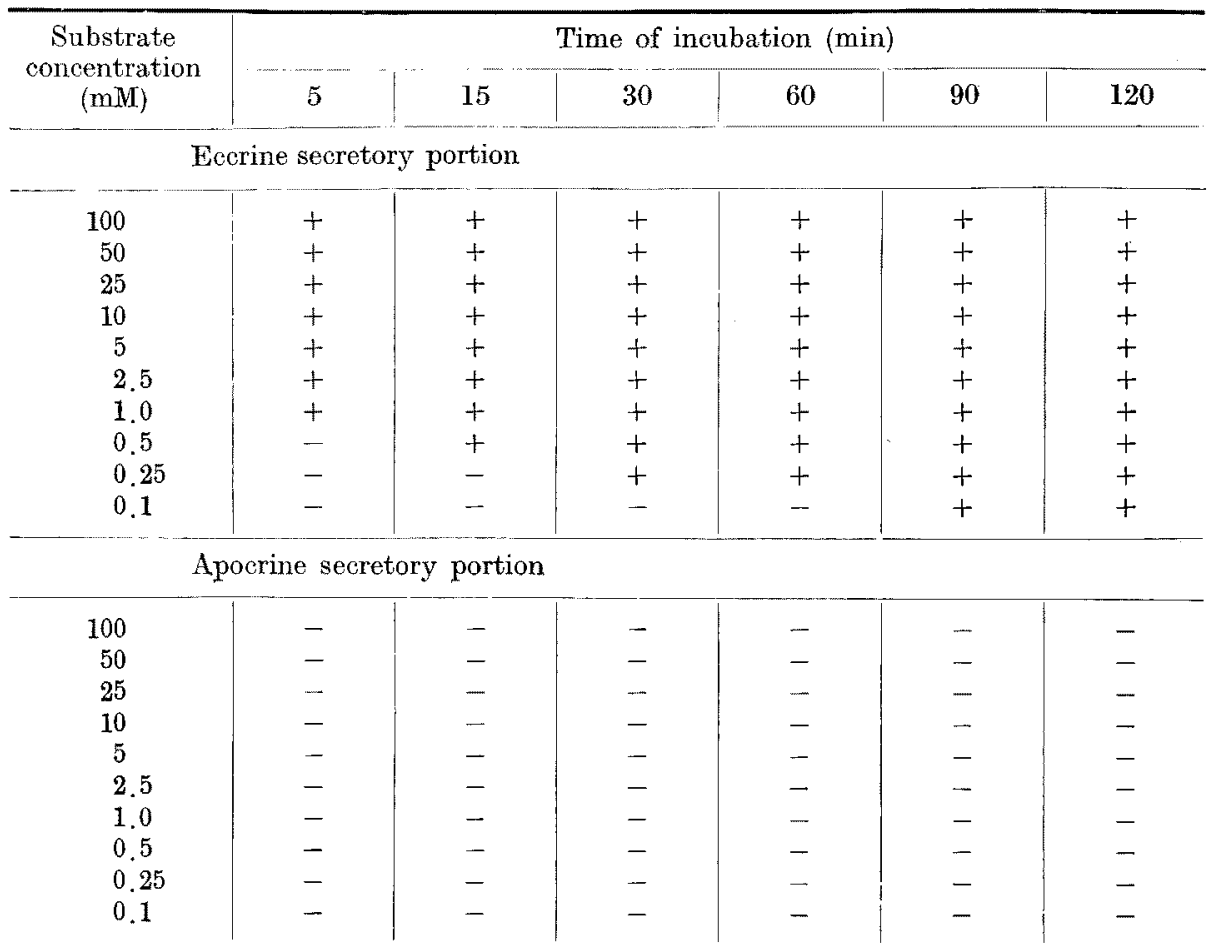

an average molecular weight of 500,000 to $5,000,000$ was effective in shortening the incubation time necessary for the appearance of the reaction in the eccrine secretory portion, and made it possible for the reaction to appear in the apocrine secretory portion (Table 6). The most prominent effect was obtained by the addition of dextran with an average molecular weight of 40,000 to 110,000 (Fig. 2).

The above results were obtained in either substrate solution series.

\section{4) Specificity test}

In this experiment, the substrate solution was composed of $100 \mathrm{mg}$ of glucose1-phosphate, $15 \mathrm{mg}$ of $5^{\prime}$-adenylic acid, $15 \mathrm{mg}$ of sodium fluoride, $20 \mathrm{mg}$ of ethylenediaminetetraacetic acid, 1,000 $\mathrm{mg}$ of dextran with an average molecular weight of 40,000 and $10 \mathrm{ml}$ of $0.05 \mathrm{M}$ acetate buffer at $\mathrm{pH} 5.8$.

The addition of phlorizin in a final concentration of $10 \mathrm{mM}$ to the substrate solution completely inhibited the reaction in the apocrine and eccrine secretory portions. When glucose was added in $20 \mathrm{mM}$, a competitive inhibition was observed.

On the other hand, serial sections were incubated in the substrate solution for 90 minutes at $37^{\circ} \mathrm{C}$, and then immersed in $0.5 \%$-amylase solution buffered at $\mathrm{pH}$ 5.8 for 60 minutes at $37^{\circ} \mathrm{C}$. The reaction product was digested. 
TABLE 4. Effect of dextrin (50 mg per ml) on a-glucan phosphorylase reaction in the presence of $5^{\prime}$-adenylic acid in $3 \mathrm{mM}$

\begin{tabular}{|c|c|c|c|c|c|c|}
\hline \multirow{2}{*}{$\begin{array}{c}\text { Substrate } \\
\text { concentration } \\
(\mathrm{mM})\end{array}$} & \multicolumn{6}{|c|}{ Time of incubation (min) } \\
\hline & 5 & 15 & 30 & 60 & 90 & 120 \\
\hline \multicolumn{7}{|c|}{ Eccrine secretory portion } \\
\hline $\begin{array}{c}100 \\
50 \\
25 \\
10 \\
5 \\
2.5 \\
1.0 \\
0.5 \\
0.25 \\
0.1\end{array}$ & $\begin{array}{l}+ \\
+ \\
+ \\
+ \\
+ \\
+ \\
+ \\
- \\
- \\
-\end{array}$ & $\begin{array}{l}+ \\
+ \\
+ \\
+ \\
+ \\
+ \\
+ \\
+ \\
- \\
-\end{array}$ & $\begin{array}{l}+ \\
+ \\
+ \\
+ \\
+ \\
+ \\
+ \\
+ \\
- \\
-\end{array}$ & $\begin{array}{l}+ \\
+ \\
+ \\
+ \\
+ \\
+ \\
+ \\
+ \\
+ \\
-\end{array}$ & $\begin{array}{l}+ \\
+ \\
+ \\
+ \\
+ \\
+ \\
+ \\
+ \\
+ \\
+\end{array}$ & $\begin{array}{l}+ \\
+ \\
+ \\
+ \\
+ \\
+ \\
+ \\
+ \\
+ \\
+\end{array}$ \\
\hline \multicolumn{7}{|c|}{ Apocrine secretory portion } \\
\hline $\begin{array}{c}100 \\
50 \\
25 \\
10 \\
5 \\
2.5 \\
1.0 \\
0.5 \\
0.25 \\
0.1\end{array}$ & $\begin{array}{l}- \\
- \\
- \\
- \\
- \\
- \\
- \\
- \\
- \\
-\end{array}$ & $\begin{array}{l}- \\
- \\
- \\
- \\
- \\
- \\
- \\
- \\
- \\
-\end{array}$ & $\begin{array}{l}- \\
- \\
- \\
- \\
- \\
- \\
- \\
- \\
- \\
-\end{array}$ & $\begin{array}{l}- \\
- \\
- \\
- \\
- \\
- \\
- \\
- \\
- \\
-\end{array}$ & $\begin{array}{l}- \\
- \\
- \\
- \\
- \\
- \\
- \\
- \\
- \\
-\end{array}$ & $\begin{array}{l}- \\
- \\
- \\
- \\
- \\
- \\
- \\
- \\
- \\
-\end{array}$ \\
\hline
\end{tabular}

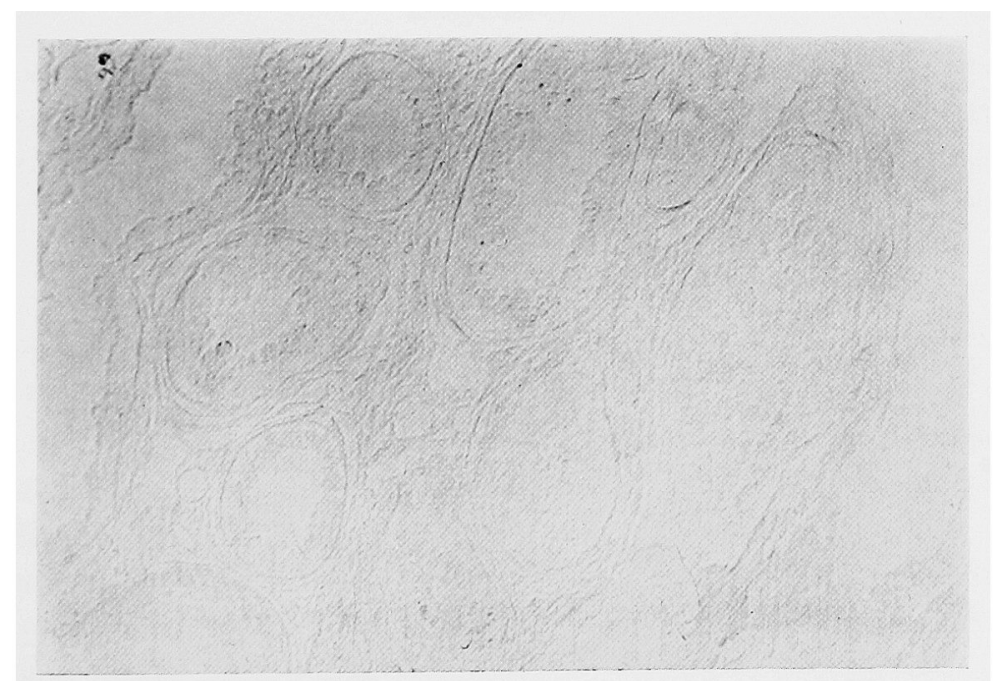

Fig. 1. a-Glucan phosphorylase reaction of an apocrine sweat gland from a 21 year-old male. Section was incubated for $90 \mathrm{~min}$ at $37^{\circ} \mathrm{C}$ in the substrate solution, which contained glycogen in $100 \mathrm{mg}$ per ml. No reaction is found in, the apocrine secretory portion. $\times 120$, 
TABLE 5. Effect of dextran with an average molecular weight of 2,000,000/50 mg per $m l$ ) on a-glucan phosphorylase reaction in the presence of $5^{\prime}$-adenylic acid in $3 \mathrm{mM}$

\begin{tabular}{|c|c|c|c|c|c|c|}
\hline \multirow{2}{*}{$\begin{array}{c}\text { Substrate } \\
\text { concentration } \\
\text { (mM) }\end{array}$} & \multicolumn{6}{|c|}{ Time of incubation (min) } \\
\hline & 5 & 15 & 30 & 60 & 90 & 120 \\
\hline \multicolumn{7}{|c|}{ Eccrine secretory portion } \\
\hline 100 & + & + & + & + & + & + \\
\hline 50 & + & + & + & + & + & + \\
\hline 25 & + & + & + & + & + & + \\
\hline 10 & + & + & + & + & + & + \\
\hline 5 & + & + & + & + & + & + \\
\hline 2.5 & + & + & + & + & + & + \\
\hline 1.0 & + & + & + & + & + & + \\
\hline 0.5 & - & + & + & + & + & + \\
\hline 0.25 & - & - & + & + & + & + \\
\hline 0.1 & - & -- & - & - & + & + \\
\hline
\end{tabular}

Apocrine secretory portion

\begin{tabular}{|c|c|c|c|c|c|c|}
\hline 100 & - & - & - & + & + & + \\
\hline 50 & - & - & - & - & - & - \\
\hline 25 & - & - & - & - & - & - \\
\hline 10 & - & - & - & - & - & - \\
\hline 5 & - & - & - & - & - & - \\
\hline 2.5 & - & - & $-!$ & - & - & - \\
\hline 1.0 & - & - & - & - & - & - \\
\hline 0.5 & - & - & - & - & - & - \\
\hline 0.25 & -- & - & - & - & - & - \\
\hline 0.1 & - & - & - & - & - & - \\
\hline
\end{tabular}

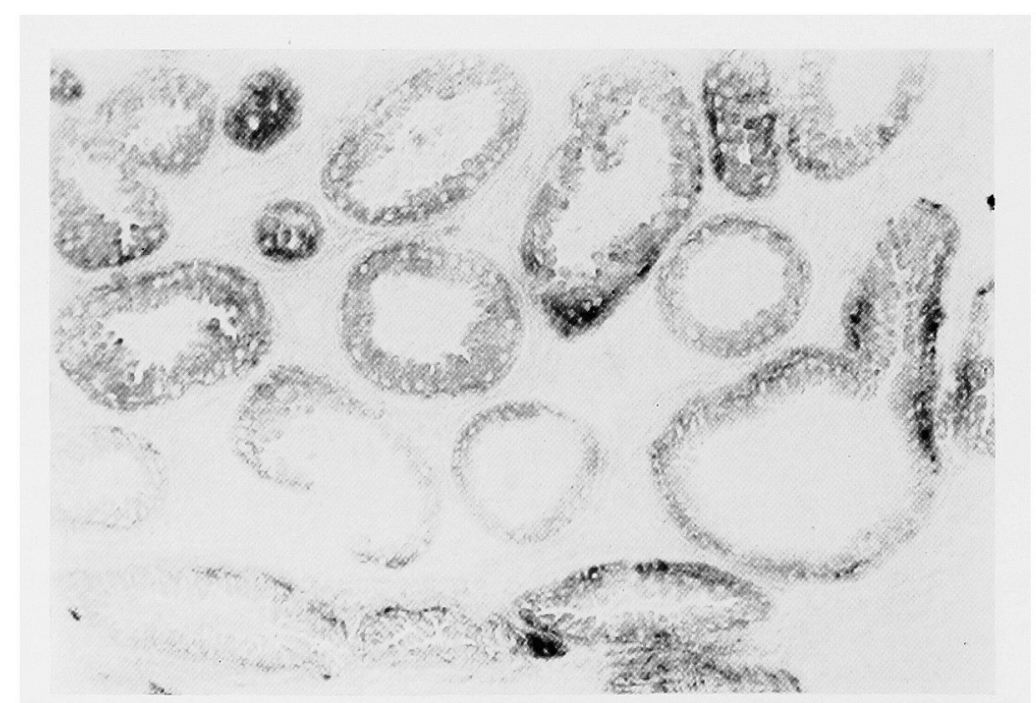

Fig. 2. $\alpha$-(t)lucan phosphorylase reaction of an apocrine sweat gland from a 21 year-old male. Section was incubated for $90 \mathrm{~min}$ at $37^{\circ} \mathrm{C}$ in the substrate solution, which contained dextran with an average molecular weight of 40,000 in $100 \mathrm{mg}$ per $\mathrm{ml}$. The apocrine secretory portion is intensely reactive. $\times 120$. 
TABLE 6. Effect of dextran with an average molecular weight of $40,000(50 \mathrm{mg}$ per $m l)$ on a-glucan phosphorylase reaction in the presence of $5^{\prime}$-adenylic acid in $3 \mathrm{mM}$

\begin{tabular}{|c|c|c|c|c|c|c|}
\hline \multirow{2}{*}{$\begin{array}{l}\text { Substrate } \\
\text { concentration } \\
(\mathrm{mM})\end{array}$} & \multicolumn{6}{|c|}{ Time of incubation (min) } \\
\hline & 5 & 15 & 30 & 60 & 90 & 120 \\
\hline \multicolumn{7}{|c|}{ Eccrine secretory portion } \\
\hline 100 & + & + & + & + & + & + \\
\hline 50 & + & + & + & + & + & + \\
\hline 25 & + & + & + & + & + & + \\
\hline 10 & + & + & + & + & + & + \\
\hline 5 & + & + & + & + & + & + \\
\hline 2.5 & + & + & + & + & + & + \\
\hline 1.0 & + & + & + & $t$ & + & + \\
\hline 0.5 & + & + & + & + & + & + \\
\hline 0.25 & - & + & + & + & + & + \\
\hline 0.1 & - & - & - & - & + & + \\
\hline \multicolumn{7}{|c|}{ Apocrine secretory portion } \\
\hline 100 & - & - & + & + & + & + \\
\hline 50 & - & - & - & + & + & + \\
\hline 25 & - & - & - & + & + & + \\
\hline 10 & - & - & - & + & + & + \\
\hline 5 & - & - & - & - & + & + \\
\hline 2.5 & - & - & - & - & - & - \\
\hline 1.0 & - & - & - & - & - & - \\
\hline 0.5 & - & - & - & - & - & - \\
\hline 0.25 & - & - & $-\cdots$ & - & - & - \\
\hline 0.1 & - & - & - & - & - & - \\
\hline
\end{tabular}

\section{Discussion}

a-Glucan phosphorylase catalyzes the synthesis or degradation of amylosetype molecules by transglucosylation. The equilibrium constant for this reaction is given by

$$
K=\frac{\left[\left(\mathrm{C}_{6} \mathrm{H}_{10} \mathrm{O}_{5}\right)_{n+1}\right]\left[\mathrm{HPO}_{4}^{--}\right]}{\left[\left(\mathrm{C}_{6} \mathrm{H}_{10} \mathrm{O}_{5}\right)_{n}\right]\left[\text { Glucose-1-phosphate }{ }^{--}\right]}
$$

Since each molecule of polysaccharide is both a reactant and a product, $K$ is determined by the ratio of phosphoric acid to glucose-1-phosphate. When the concentration of phosphoric acid is relatively high in relation to the concentration of glucose-1-phosphate, glycogen is broken down by the enzyme. In contrast, when the concentration of glucose-1-phosphate is relatively high as compared with the concentration of phosphoric acid, the reaction proceeds to glycogen formation. a-Glucan phosphorylase does not act upon glucose-1-phosphate except in the presence of a primer such as glycogen, dextrin, dextran or amylopectin. In other words, the enzyme needs an acceptor to which new glucosidic units can be transferred from glucose-1-phosphate. ${ }^{11}$ On the basis of these biochemical data, Takeuchi and Kuriaki² devised a method for the histochemical demonstra- 
tion of $\alpha$-glucan phosphorylase activity. Their substrate solution contained glycogen as a primer. Erönkö and Palkama ${ }^{12}$ stated that the addition of glycogen to the substrate solution promoted glycogenesis during incubation. With the scintillation method, Meijer ${ }^{13}$ showed that in the histochemical method ${ }^{14} \mathrm{C}$-glycogen is not used as a primer, and that the glycogen already present in the tissue serves as a primer. As shown in Tables 3-5, the addition of glycogen, dextrin, dextran with a higher molecular weight or amylopectin was scarcely effective in shortening the incubation time necessary for reaching the reaction end point. In contrast, when dextran with a lower molecular weight was added, the incubation time necessary for reaching the reaction end point was shortened. These results suggest that polysaccharides with a relatively high molecular weight cannot penetrate into tissue sections, and consequently cannot serve as a primer.

On the other hand, when phlorizin or glucose was introduced into the dextran (with an average molecular weight of 40,000)-containing substrate solution, the reaction was completely inhibited. When the control substrate solution without substrate was employed, no positve reaction was found. Accordingly, the present results indicate that the staining in sections obtained by the addition of dextran to the substrate solution is due exclusively to the activity of $a$-glucan phosphorylase.

\section{References}

1) Yin, H.C. \& Sun, C.N. Histochemical method for the detection of phosphorylase in plant tissue. Science, 1947, 105, 650 .

2) Takeuchi, T. \& Kuriaki, H. Histochemical detection of phosphorylase in animal tissues. J. Histochem. Cytochem., 1955, 3, 153-160.

3) Takeuchi, T., Higashi, K. \& Watanuki, S. Distribution of amylophosphorylase in various tissues of human and mammalian organs. J. Histochem. Cytochem., 1955, $3,485-491$.

4) Takeuchi, T. Histochemistry of intracellular polysaccharide synthesis. Ann. Histochim., $1962,7,61-79$.

5) Braun-Falco, $O$. Ủber die Fähigkeit der menschlichen Haut zur Polysaccharidsynthese, ein Beitrag zur Histotopochemie der Phosphorylase. Arch. Klin. exp. Derm., 1956, 202, 163-170.

6) Ellis, R.A. \& Montagna, W. Histology and eytochemistry of human skin. XV. Sites of phosphorylase and amylo-1,6-glucosidase activity. J. Histochem. Cytochem., 1958, 6, 201-207.

7) Goltz, W.F., Fusaro, R.M., Blazejovsky, R. \& Jarvis, J. Pathways of carbohydrate metabolism in normal and neoplastic cutaneous ectoderm, a histochemical study. $J$. invest. Derm., 1959, 33, 337-345.

8) Wells, G.C., Sanderson, K.V. \& MoCabe, I.M. The histochemical localization of phosphorylase in skin. Brit. J. Derm., 1961, 73, 337-345.

9) Sasai, Y. Histochemical demonstration of phosphorylase $a$, phosphorylase $b$ and phosphorylase kinase in normal human skin. Tohoku J. exp. Med., 1965, 85, 160170.

10) Montagna, W. The Structure and Function of Skin, 2nd ed., Academic Press, New York, 1962, p. 406.

11) Bown, D.H. \& Cori, C.F. Animal and plant polysaccharide phosphorylases. In: The Enzymes, vol. 5, edited by P.D. Boyer, H. Lardy \& K. Myrbäck, 2nd ed., Academic 
Press, New York, 1961, p. 207.

12) Erönkö, O. \& Palkama, A. Improved localization of phosphorylase by the use of polyvinylpyrrolidone and high substrate concentration. J. Histochem. Cytochem., $1961,9,585$.

13) Meijer, A.E.F. Improved histochemical method for the demonstration of the activity of a-glucan phosphorylase. I. The use of glucosyl acceptor dextran. Histochemie, 1968, 12, 244-252. 